\title{
Algunos apuntes sobre el uso del sonido en el cine de Jean-Luc Godard*
}

\author{
Ángel Quintana \\ Universidad de Gerona \\ angel.quintana@udg.edu
}

\begin{abstract}
Resumen
Jean Luc Godard es uno de los grandes creadores de formas del cine contemporáneo y uno de los cineastas que más ha reflexionado en sus obras sobre la relación entre la imagen y sonido. A partir del concepto de interferencia sonora, el texto expone algunas de las estrategias utilizadas por el cineasta para romper con el naturalismo y la espectacularidad sonora propios del cine convencional. Godard trabaja la interferencia sonora situando al mismo nivel el sonido ambiente y los diálogos. Otras veces, busca un ritmo peculiar entre ellos. También le interesa filmar la música durante los ensayos como proceso creativo, tal como hizo con la composición del tema "Simpathy for the devil", de los Rolling Stones. Finalmente, desde la militancia y el compromiso, acaba utilizando el sonido como elemento para establecer una metáfora del carácter político sobre la dialéctica entre ver una imagen y escuchar un sonido.
\end{abstract}

Palabras clave

Godard, cine contemporáneo, interferencia sonora, Rolling Stones.

\section{Some notes on the use of sound in the cinema of Jean-Luc Godard}

\begin{abstract}
Jean Luc Godard is one of the great creators of contemporary film forms and one of the filmmakers who has reflected more in his works on the relation between image and sound. From the concept of sound interference, the text exposes some of the strategies used by the filmmaker to break with the naturalism and the spectacular sound of conventional cinema. Godard works on sound interference by placing the ambient sound and dialogues at the same level. At other times, he search a peculiar rhythm between them. He is also interested in filming music during rehearsals as a creative process, as he did with the composition of the Rolling Stones theme "Simpathy for the devil". Finally, from militancy and commitment, he ends up using sound as an element to establish a metaphor for the political character of the dialectic between seeing an image and hearing a sound.
\end{abstract}

Keywords

Godard, contemporary cinema, sound interference, Rolling Stones.

* Recibido: 15 de abril de 2017 / Aceptado: 31 de mayo de 2017. 
Ángel Quintana. Algunos apuntes sobre el uso del sonido en el cine de Jean-Luc Godard.

\section{Algumas notas sobre o uso do som no cinema de Jean-Luc Godard}

Resumo

Jean Luc Godard é um dos grandes criadores de formas do cinema contemporâneo e um dos cineastas que tem mais refletido em seus trabalhos sobre a relação entre imagem e som. A partir do conceito de interferências sonoras, o texto expõe algumas das estratégias utilizadas pelo cineasta de romper com o naturalismo eo som espetacular de cinema convencional. Godard trabalha em interferências sonoras, colocando ao mesmo nível o som ambiente e o diálogo. Em outras ocasiões, ele procura um ritmo particular entre eles. Também está interessado em filmar a música como um criativo durante o processo de ensaios, como fiz com a composição do Rolling Stones tema "Simpathy for the Devil". Finalmente, a partir de militância e compromisso, Godard acaba usando o som como um elemento para estabelecer uma metáfora para o caráter político da dialética entre ver uma imagem e ouvir um som.

Palavras-chave

Godard, contemporary cinema, sound interference, Rolling Stones. 


\section{La dialéctica sonido/imagen}

En los años de la efervescencia política posteriores a mayo de 1968, Jean Luc Godard redactó un texto para presentar y promocionar su película militante, British Sounds (1970). En el texto, afirmaba:

El film es básicamente la crónica de un sonido que se opone a otro sonido: un sonido revolucionario se opone a un sonido imperialista. En toda película siempre se pone de manifiesto una dialéctica, que siempre funciona como resultado de la lucha existente entre las imágenes y los sonidos (Godard en Bergala, 1985: 337-338).

En el cine industrial, la mayoría de los cineastas entienden el sonido desde una perspectiva naturalista y piensan que debe ser utilizado como referente de la realidad. En determinadas películas de género, también puede ser visto como un elemento clave para reforzar la perspectiva espectacular o emocional del discurso. La creación de determinados efectos sonoros sirve para amplificar la intensidad emocional de aquello que no se ha podido llevar a cabo mediante la puesta en escena o mediante las estrategias del montaje. En el cine de Jean Luc Godard, en cambio, el sonido siempre funciona a partir de una relación dialéctica respecto a la imagen. Esta dialéctica genera una tensión y esta tensión es uno de los aspectos fundamentales que nos pueden ayudar a entender la complejidad de la obra cinematográfica del cineasta de la Nouvelle Vague. En sus trabajos, los diálogos suelen estar tapados por el impacto del sonido directo y la sonoridad actúa como el pretexto que permite crear una musicalidad que acaba definiendo o modulando el ritmo interno de la obra.

Tal como afirmó Colin MacCabe en el transcurso de un estudio sobre la implicación política de la obra de Godard, la cuestión fundamental no reside en "cómo llevar a cabo una película política sino en cómo poder hacer cine políticamente" (1980: 35). A partir de esta perspectiva, debemos tener presente que toda película no es únicamente el resultado del proceso de construcción de una fábula o de un relato, puesto que toda obra interesante debe ser vista como el resultado de un proceso de autoconsciencia y de investigación interna sobre el uso del lenguaje. En el caso de Godard, todo este trabajo de investigación no sólo se lleva a cabo a partir de la innovación formal en el uso de la puesta en escena o mediante la transgresión de los vínculos que se establecen durante el proceso de montaje. La investigación también se hace efectiva mediante el uso del sonido.

Desde À bout de souffle (1960), la mítica película que inauguró su filmografía, hasta Adieu au langage (2014), su último trabajo hasta la fecha, rodado mediante el uso de cámaras 3D, Jean Luc Godard no ha cesado de investigar. Toda su filmografía experimenta en los fundamentos del lenguaje del cine y en el uso de las imágenes mediante las innovaciones tecnológicas. Durante cerca de sesenta 
años, el cineasta ha establecido una filmografía única, en cuyo interior se encuentran algunos de los ejercicios más rigurosos de análisis y deconstrucción sonora que se han llevado a cabo en la historia del cine. Analizar el lenguaje expresivo del cine implica buscar nuevas formas estilísticas que establezcan vínculos y relaciones entre la imagen y el sonido. Todos los vínculos pueden ayudar a estimular la posibilidad de que surjan nuevas propuestas de sentido. Toda película se transforma en un espacio de acción política porque, en su interior, se pone de manifiesto una clara voluntad de pensar la imagen y el sonido como elementos de innovación formal o como unos simples instrumentos de transgresión de las políticas institucionales que han marcado la existencia de los discursos hegemónicos.

\section{Las interferencias sonoras}

En su libro Godard au travail, Alain Bergala (2006) afirma que, a lo largo de la historia del cine, ha habido dos modelos de cineastas rupturistas. El primer modelo sería el de los cineastas que imaginan de forma conceptual la ruptura y la programan como elemento esencial de su obra. En el contexto de la Nouvelle Vague, un caso paradigmático de este modelo sería Alain Resnais. Su trabajo de innovación se llevó a cabo en Hiroshima mon amour (1959) o en L'année dernière à Marienbad (1961), a partir de textos de Marguerite Duras y Alain Robbe-Grillet, respectivamente. En cambio, existen otros cineastas, como Jean Luc Godard o Roberto Rossellini, que necesitan encontrar el accidente, es decir, el hecho causal o la resistencia técnica y material. Una serie de elementos imponderables los ayudan a poder encontrar otro modo de hacer que les permita llevar a cabo una serie de innovaciones.

El descubrimiento de las posibilidades generadas mediante el trabajo con el sonido nace de la resistencia técnica y de las dificultades económicas. En 1959, cuando Godard rueda À bout de souffle (1960), lo hace sin sonido directo. Filma la imagen y se propone llevar a cabo un trabajo posterior de registro en estudio, tanto de los diálogos como del sonido ambiente. Mientras el proceso de rodaje fue rápido -veintiún días laborales- el proceso de montaje se complicó porque fue necesario reconstruir todo el sonido y grabar todos los diálogos. En el momento de plantearse de qué modo se debía llevar a cabo el montaje sonoro -esa dialéctica entre las imágenes filmadas y los sonidos grabados-, Godard decidió potenciar un principio estético basado en la superposición de sonidos. Un método que, a partir de ese momento, no dejará de utilizar a lo largo de su obra. Para Godard, se trataba de aceptar que los sonidos ambientales, incluso los más perturbadores, como los sonidos del motor de un vehículo durante un rodaje en exteriores o los ruidos de los platos y vasos en el interior de una escena que transcurre en restaurante, deben anular la inteligibilidad de los diálogos. Las conversaciones entre los personajes no pueden ocupar un espacio preferencial en la banda 
sonora, sino que deben estar mezcladas con el sonido ambiente, aunque éste impida al espectador escuchar los diálogos. No le interesa la claridad del diálogo como elemento de sentido, sino la posibilidad de dignificar la materia sonora. El gran giro estético de la obra de Godard consistió en la posibilidad de dar relevancia a la noción de interferencia sonora (Bergala, 2006: 53).

Al empezar a explorar las posibilidades estéticas de la interferencia sonora, Jean Luc Godard reivindica un modelo de montaje sonoro cuyo origen se encuentra en los años 1930, en el momento en que se institucionalizaron las formas de uso del sonido grabado en el cine. Cuando apareció el cine sonoro, uno de los principales debates que empezó a formularse fue el de la posibilidad de convertir la materia sonora -los diferentes ruidos- en una serie de elementos que pudieran provocar una clara tensión respecto al uso naturalista de los diálogos. Si observamos, por ejemplo, el uso que Jean Renoir hizo del sonido en La nuit du carrefour (1932), adaptación de una novela de Georges Simenon, podemos comprender con más claridad dicho procedimiento. La apuesta de Renoir era la de convertir los diferentes sonidos en parte de un campo sonoro que pudiese dilatar el campo visual y ofrecerle nuevas formas de significación. En los títulos de crédito, escuchamos el sonido de una moto Bugatti mezclado con el silbido de un soldador y una música que proviene del altavoz de una gramola. Renoir puso todos los sonidos al mismo nivel, sin minimizar ninguno de ellos, abriendo un camino alternativo a la deriva naturalista que empezaba a ser hegemónica en los primeros talkies americanos. Godard retomó esta lógica estética gracias al principio de que los diálogos nunca podrían llegar a ser más importantes que los sonidos provenientes del mundo real. Con À bout de souffle, Godard recreó una cierta estética del sonido ambiente que es grabado en estudio y que permite la creación de múltiples efectos sonoros. Curiosamente, todo este trabajo de reconstrucción del sonido desde el estudio le sirve para inventar una estética del sonido directo, antes de poder acceder a los aparatos técnicos que le permitieran empezar a grabar el sonido directo. Su primera película rodada con sonido directo sincrónico es Une femme est une femme (1961) y la película que radicalizó el uso del sonido fue Vivre sa vie (1962). En esta última, Godard empezó a trabajar con las modulaciones e interferencias en el uso de la voz en off y la voz over. Esta técnica lo condujo a experimentar en las posibles distorsiones de la voz. El momento fundacional de esta técnica tuvo lugar en Alphaville (1965), película rodada en el moderno París de la época, donde apareció la figura de un ordenador/robot que se expresa con una grave voz mecánica, simulando la existencia de un poder computacional que controla el mundo de esa ciudad futurista.

La creación de una materia sonora y las distorsiones de la voz provocan en la obra de Godard una fuerte tensión que aumenta cuando establece una relación del sonido con la música. A lo largo de toda la obra de Godard, las músicas siempre 
han tenido un papel muy destacado. El cineasta trabaja con diferentes tipos de músicas y siempre ha demostrado un claro eclecticismo en sus elecciones afectivas. A lo largo de su cine, podemos encontrar referencias a la chanson française, sobre todo a partir de temas de Jean Ferrat y Léo Ferré, junto con diferentes piezas de música clásica como el Concierto de clarinete K.622, de Mozart, en À bout de souffle o el Requiem, de Gabriel Fauré, en Passion (1982). En algunas películas ha trabajado con compositores expertos en la creación de bandas sonoras para el cine, como es el caso de Georges Delerue en Le Mépris (1963) o Michel Legrand en Bande à part (1964). La música le sirve para establecer diálogos sonoros, pero también para crear nuevas modulaciones rítmicas con la imagen, que se ponen de manifiesto en el proceso de montaje. También le permite investigar en torno a la presencia de otros elementos que crean una concentración del espacio sonoro -sonido ambiente y diálogos. En algunos casos, es capaz de crear una verdadera sinfonía urbana a partir de una pieza musical, como en la admirable Lettre à Freddy Buache (1982), donde los colores, movimientos y formas de la ciudad suiza de Lausana intentan establecer una coreografía con el ritmo in crescendo de el Bolero de Ravel.

En otros casos, Godard utiliza una misma música de diferentes formas. Un ejemplo significativo es el uso que hace de las mismas piezas en dos películas realizadas en dos momentos muy alejados de su propia filmografía. Godard utiliza fragmentos de los cuartetos 7, 9, 10, 14 y 15 de Ludwig van Beethoven en Une femme mariée (1964) y en Prénom Carmen (1983). Pero en Prénom Carmen, Godard filma todo el proceso de cómo toman forma los cuartetos de Beethoven durante los trabajos de ensayo llevados a cabo por los miembros del Quartet Prat. El interés del cineasta en esta película no es otro que el de mostrar como la obra se ensaya, se prepara, cómo toma forma y madura durante el proceso de preparación del concierto por parte de un grupo de intérpretes. Godard reutiliza los mismos temas sonoros de Beethoven a partir de dos premisas fundamentales. La primera es que "mientras el concierto es la lucha de todos los instrumentos contra todos, el cuarteto es sobre todo una manifestación del cuerpo a cuerpo" (Liandrat-Guigues y Leutrat, 1994: 70). La segunda premisa es que la regularidad rítmica y repetitiva de algunos de los cuartetos de Beethoven puede ser el elemento ideal para poder crear una tensión entre el tempo interno y el ritmo de la propia película. En Une femme mariée, el tema de la monotonía que surge en las relaciones de la pareja estalla en las elecciones llevadas a cabo mediante la puesta en escena. Este sentimiento se encuentra acentuado por el uso de la música. En cambio, en Prénom Carmen, donde el tema subliminal es el mito de Carmen, entendido como manifestación de un modelo de mujer carnal, el hecho de substituir la música de la ópera de Bizet por los cuartetos de Beethoven tiene que ver con esa lucha cuerpo a cuerpo inherente a la ejecución de los cuartetos durante el proceso de ensayo. Tenemos que recordar que, en los títulos de crédito de Prénom 
Carmen, se indica que no nos encontramos ante una película dirigida o puesta en escena, sino ante una película compuesta por Jean Luc Godard. Esta idea de la película compuesta por el cineasta no hace más que reforzar la reflexión de que todo su trabajo gira en torno a la cuestión de la carnalidad del mito de Carmen. Tal como ha indicado el propio cineasta:

La música no debe expresar el alma, sino el cuerpo de las mujeres. Es una música fundamental que permite guiar una acción en la que los músicos son tan actores como los otros intérpretes. No es una música que acompaña la película, es una película hecha con música. Mi productor era Carmen y mi guionista fue Beethoven (Godard en De Baecque, 2010: 617-618).

La investigación en torno al uso de la música como banda sonora tiene en la filmografía de Godard un momento clave cuando el cineasta establece un acuerdo con la compañía discográfica alemana ECM, de Manferd Eicher. Godard ha explicado que, cuando conoció el catálogo de la compañía, se sintió fascinado por la exigencia de la selección de música llevada a cabo por ECM. Sabía que no se trataba de una música pensada para el cine, pero intuía que, a partir de ella, podría llevar a cabo interesantes trabajos sonoros. Al productor alemán Manferd Eisher, en cambio, le gustaba el modo en que Godard podía llegar a yuxtaponer el sonido, la luz, el texto y la música (Jullier, 2004: 272-273). En las bandas sonoras que Godard construye desde 1990, vemos cómo utiliza obras de Arvo Pärt, Paul Hindemith y Mederith Monk, sacadas del amplio catálogo alemán.

Por otra parte, la compañía ECM editó, en 1998, en diferentes CDs, toda la banda sonora íntegra -música, diálogos y sonido ambiente- de su producción de cuatro horas y media de duración Histoire(s) du cinéma (1988-1998). La edición de esta banda sonora supuso un reto, porque se trataba de escuchar el sonido de una producción compleja, surgida a partir de una cierta idea del collage en la que el aspecto de la tensión dialéctica ha sido siempre un elemento fundamental. Por otra parte, demostraba que la musicalidad del cine de Godard no estaba determinada por las músicas concretas, sino por la cadencia de las voces distorsionadas -en Histoire(s) du cinéma, estaba muy presente la voz del propio Jean-Luc Godard- junto al uso de sonidos -el ritmo del teclear de la máquina de escribir eléctrica marcó todo el inicio de la serie-, las canciones -entre ellas, "Palabras para Julia", interpretada por Paco Ibáñez-y las músicas. La separación del sonido de la imagen para su venta como CD del catálogo ECM provocó una sensación extraña. De todos modos, la edición certificaba que el trabajo sonoro llevado a cabo por Godard podía ocupar un lugar clave dentro de las investigaciones sobre el concepto de espacio sonoro en el interior del mundo de la cultura contemporánea.

La complejidad del trabajo en torno a la estética basada en la idea de interferencia sonora, así como el deseo de convertir la forma en un camino hacia la autoconsciencia creativa, nos llevan hacia tres formas específicas del uso del sonido 
en el cine de Godard. Estos tres elementos básicos son la coreografía del sonido, la mostración del proceso creativo que da origen a la música y la idea de poder llegar a pensar el sonido como metáfora de índole política.

\section{La coreografía del sonido}

En los años 1920, cuando, en el contexto de las vanguardias, se articularon las grandes teorías sobre el montaje cinematográfico, surgió la idea de que la unión de las imágenes, la creación de intervalos y las repeticiones de motivos visuales podían llegar a crear un ritmo interno del que dependía la musicalidad de la película. Una parte de estos debates surgieron en torno a un cine mudo que establecía relaciones con los movimientos artísticos de la época -cubismo y dadaísmo. En los manifiestos cinematográficos se hablaba de que la película ideal era la obra capaz de constituirse en una sinfonía visual hecha de imágenes rimadas (SánchezBiosca, 1996: 72-73). En Rusia, después de la revolución, el teórico Sergei M. Eisenstein, quién creó las bases de una sólida teoría del montaje, no cesó de utilizar los conceptos de música y ritmo para poder hablar del efecto que se producía mediante la unión entre diferentes imágenes. En un artículo escrito en 1937, explica que todo montaje tiene dos funciones clave: la función narrativa y la función rítmica. A partir de esta premisa, Eisenstein retomó las reflexiones expuestas en una conferencia que impartió en la Universidad de la Sorbonne de París en 1930, en la que establecía una clasificación de los modelos de montaje ordenados por su secuencia cinética. Los modelos de montaje propuestos eran métrico, rítmico, tonal (melódico), armónico e intelectual, entendido este último como una nueva modalidad dentro del desarrollo del montaje armónico hacia la creación de lo que se conocía como armónicos significativos (Eisenstein, 2001: 12-13). Hoy, es curioso observar esta clasificación establecida por Eisenstein en los años del nacimiento del cine sonoro. De hecho, nos permite comprobar cómo, desde una cultura claramente visual, el cine puede acabar desembocando hacia el concepto de ritmo extraído de la cultura musical y del mundo de la danza.

Godard resalta las reflexiones de Eisenstein cuando afirma que el trabajo llevado a cabo en el ámbito del montaje puede ser ante todo musical. En toda película se puede "pasar de un plano a otro por un motivo dramático, y es la conexión establecida por Eisenstein la que se opone de un modo con el otro y las enlaza de forma indisoluble. El paso de un plano general a un primer plano se convierte posteriormente en el paso en música de un tono mayor a la de un tono menor" (Liandrat-Guigues y Leutrat, 1994: 69).

El cine de Godard yuxtapone esta idea del ritmo en el montaje con la idea de crear un ritmo interno que funcione como un elemento interior de la puesta en escena. A lo largo de su filmografía, son diferentes las coreografías más o menos 
explícitas en las que trabaja el ritmo sonoro como elemento que marca el ritmo de la puesta en escena. En Bande à part, por ejemplo, pone en escena una famosa escena de danza entre Ana Karina, Sami Frey y Claude Brasseur que empieza con el sonido ambiente, sigue con el sonido de los golpes de unos cuerpos que entrechocan y acaba con una danza al ritmo de la música que suena desde la jukebox de un bar. En otro momento de la misma película, Godard establece otras coreografías en torno a una mesa de billar. En otras ocasiones, la búsqueda del ritmo aparece acentuada por el uso del sonido ambiente hasta llegar a los límites de lo burlesco, tal como pone de manifiesto Godard, por ejemplo, en Soigne ta droite (1987). En esta película, la comicidad vendría determinada por el uso del sonido, siguiendo de este modo las lecciones establecidas años antes por un cineasta como Jacques Tati. La idea de collage sonoro como elemento articulador del sonido a partir de diferentes modulaciones sonoras entre distintos modelos de registro es una técnica que Godard utilizará en sus últimas películas. Tal como afirmaba Román Gubern, en algunas obras de Godard como Made in USA (1966), la idea visual consistía en ir hacia la no figuración mediante la destrucción del argumento por la vía del absurdo, convirtiendo los personajes en simples ectoplasmas y añadiendo a la presencia de diferentes collages ópticos, una serie de collages de carácter sonoro que se basan en la sobredimensión del sonido, hasta el punto de llegar a crear auténticos "torrentes acústicos" (Gubern, 1969: 92). En una película como Film socialisme (2010), en la que Godard trabaja mediante el uso de diferentes texturas de las imágenes -video de baja definición, imágenes capturadas desde teléfonos móviles, imágenes de alta definición- también podemos llegar a ver cómo se establece un juego entre los diferentes niveles cualitativos del propio sonido.

\section{La música como proceso creativo}

En junio de 1968, Godard se instala en Londres con el remordimiento de tener que abandonar los debates políticos que habían estallado en París, como consecuencia de mayo del 68. Su propósito es rodar una película con los Rolling Stones. Unos meses antes, en marzo, Godard se entrevistó con Mick Jagger y le propuso la idea de capturar el proceso de grabación del nuevo disco del grupo, Beggars Banquet. Las sesiones de grabación se efectuaron en el Olympic Recording Studio de Londres. La idea de Godard consistía en poder mostrar a los Stones trabajando en la preparación del disco, junto con algunos momentos creativos que funcionaran como una especie de tracks de carácter político sobre diferentes formas de lucha anticapitalista, dando cierta presencia al movimiento de los Black Panthers y reflexionando sobre las consecuencias que tenía la crisis de ciertos valores de la civilización occidental. 
El rodaje con los Stones se efectuó a lo largo de tres noches, durante las cuales los miembros del grupo estaban dando forma a uno de los temas más importantes de su trayectoria musical, "Sympathy for the devil". Godard utilizó una cámara con una gran carga de película, para poder llegar a filmar de forma ininterrumpida hasta doce minutos de metraje por toma. Un equipo ligero se encargó del registro del sonido. Durante las jornadas de registro, Mick Jagger, Keith Richards, Brian Jones, Charlie Watts y Bill Wyman retomaron de forma obsesiva algunos acuerdos, improvisaron diferentes fragmentos instrumentales, empezaron a dar forma a la letra del tema y no cesaron de investigar en torno al ritmo interno que debía tener la pieza musical. Godard se interesó por el acto de captura del proceso creativo, por las repeticiones constantes y por las variaciones creativas que podían generarse. No obstante, el cineasta prefirió mostrar la obra en proceso de creación antes que quedarse hasta los momentos finales, para poder mostrar el momento en que la obra estaba terminada. Este hecho provocó una cierta polémica con los productores, que veían la película como un gesto de promoción del nuevo disco de los Rolling Stones. Godard tituló su película One Plus One, con la idea de que aquello que el espectador podía acabar viendo era una película incompleta, en la que el tema musical de los Stones se estaba generando, pero nunca terminaba de completarse. El productor lain Quarrier, que anteriormente había trabajado como actor en diversas películas de Roman Polanski, reaccionó con brusquedad y decidió remontar algún aspecto de la película hasta acabar incluyendo, en los momentos finales, los seis minutos de la canción completa. La película acabó estrenándose con el título de Sympathy for the Devil (MacCabe, 2005: 236). A partir del momento de la publicación del disco, cuando el tema de los Stones terminó convirtiéndose en una de las obras más emblemáticas de su carrera musical, la polémica se acentuó.

La experiencia de filmar todo un proceso creativo volvería a tentar a Godard dieciocho años después, cuando, en 1985, empezó a preparar Soigne ta droite, una película insólita en la que intentó integrar diversos elementos del burlesco en el interior de su trabajo de puesta en escena. Por este motivo, contrató como protagonista a uno de los actores más representativos de la comedia popular francesa, Jacques Villeret. De nuevo, Godard se propuso filmar todo el proceso creativo generado durante la grabación de un disco. Esto le permitió crear una banda sonora deconstruída que servía de contrapunto al relato burlesco. Después de visionar el videoclip del grupo Les Rita Mitsouko, Marcia Baila, realizado por Philippe Gautier, decidió investigar la trayectoria de este dúo que alcanzó gran popularidad en la música francesa de los años ochenta. Godard tomó la decisión de filmarlos durante el momento de la preparación de la grabación y durante los ensayos de su nuevo disco The No comprendo. El dúo integrado por Catherine Ringer y Fred Chichin estableció un pacto con el cineasta. Durante dos semanas grabarían su disco en un estudio cercano a la Porte de la Villette, en París. Godard 
podía pasar por el estudio cuando lo considerara adecuado y filmar lo que creyera conveniente. El cineasta delegó el trabajo a su directora de fotografía Caroline Champetier, que acudió en repetidas ocasiones a la grabación. Champetier trabajó con una cámara de $35 \mathrm{~mm}$ y un equipo reducido de sonido. Godard no asistió a buena parte del rodaje, pero reelaboró el material durante el curso del montaje. Su intención fue la de establecer un claro paralelismo entre su propio proceso creativo de preparación de una película que no tenía ninguna dirección prefijada y el trabajo creativo en torno al uso del sonido en el disco de Les Rita Mitsouko.

En diferentes ocasiones, Godard ha justificado que el deseo de mostrar el trabajo de los músicos era un modo de llevar hasta el límite la idea expuesta por Jean Cocteau de que era preciso filmar la muerte en el momento de trabajar. El cine, incluso el cine de ficción siempre captura alguna cosa documental que transcurre frente a la cámara. Al hacerlo, redime la realidad y embalsama los gestos y movimientos de un momento determinado. La idea de que es preciso establecer un doble juego entre el acto de filmar y el acto de trabajar ha estado muy presente en todo el cine de Godard. En una entrevista publicada en el momento del estreno de Soigne ta droite, en 1987, lo expresaba con claridad:

Podría estar horas mirando a los músicos mientras trabajan. El hecho de mirarlos trabajando me permite poder llegar a imaginarme una ficción. Es una forma de imponer una mirada documental, en un momento en que el concepto de mirada parece haber perdido su sentido originario. Desde sus orígenes el cine y el documental fueron juntos. Hoy, con la necesidad de observar las cosas antes de poder hablar de ellas la mirada ha desaparecido. Estamos ante una crisis (Godard en Bergala, 1998: 123).

\section{El sonido cómo metáfora política}

En 1974, Godard se sintió atrapado en medio de una crisis creativa. La práctica del cine militante que se había llevado a cabo después del mayo del 68 por los miembros del grupo Dziga Vertov -integrado por Jean Pierre Gorin y Henri Rogerse encontraba en un callejón sin salida. Godard empezó a interesarse por la práctica del video, junto con otras posibilidades para la utilización de las imágenes y sonidos. Juntamente con su compañera sentimental, Anne Marie Mieville, creó la empresa Sonimage, que se transformó en un espacio clave para llevar a cabo las nuevas investigaciones con el video, realizadas durante una de las épocas más iconoclastas y experimentales de la carrera de Godard. A lo largo de este período, Godard mezcló el cine comprometido políticamente con la experimentación y la reflexión sobre los usos y poderes de las imágenes. Esto lo llevó a convertir Ici et ailleurs (1974) en una obra apasionante. La innovadora utilización del sonido se convirtió en el pretexto para poder articular una clarividente metáfora de carácter político, que no dejó de estar envuelta de una cierta polémica. 
Ici et ailleurs tiene como punto de partida el material que Godard rodó con el grupo Dziga Vertov en Palestina, durante la primavera de 1970. En esa ocasión, filmó a los combatientes de Al Fatah como protagonistas de una película titulada Jusqu'à la victoire. La película nunca se acabó de montar, ni fue proyectada en público. Unos años después, en 1974, Godard y Anne Marie Mieville decidieron retomar las imágenes rodadas para poder llevar a cabo un trabajo que fuera capaz de confrontar las imágenes de la revolución -entre las que había la imagen de algunos militantes palestinos muertos poco tiempo después- con las imágenes de la vida cotidiana en la sociedad francesa, una sociedad en crisis interna que vivía alienada después de las decepciones que vivieron las utopías políticas de la década de los 1960. Después de haber sido un militante activo que se movía en los círculos cercanos al maoísmo, Godard decidió comprometerse en la militancia a favor de la causa palestina, mostrándose como una figura tremendamente crítica con las políticas emprendidas por parte del Estado de Israel.

En Ici et ailleurs, Godard no cesa de interrogarse sobre el valor político de las imágenes, la función del montaje y el uso del sonido. Hay un momento de la película en la que sus preocupaciones se muestran de forma clarividente. En primer término, vemos a una familia francesa formada por un padre, una madre y una hija. Los tres están sentados en el sofá del comedor familiar y contemplan la televisión. El padre se encuentra en el paro y la madre le acusa de no ser capaz de encontrar trabajo. El cineasta se pregunta qué pasa cuando se sube el volumen de la televisión, qué se apaga y que factores se pierden de la reacción familiar. ¿De qué modo el sonido de la televisión se impone en el interior del ámbito familiar? Para poder contestar a esta cuestión, el cineasta sitúa la cámara frente a un amplificador en el que existe un contador de decibelios. Godard muestra cómo la televisión se impone frente al sonido de un pinball electrónico o cómo la mujer que trabaja en las tareas de limpieza de una fábrica decide substituir el silencio por el acto de escuchar la radio. Los sonidos saturados atraviesan la línea roja del aparato que mide los decibelios. En un momento determinado, Godard muestra en un plano frontal el contador de decibelios y nos indica de qué modo existen determinados sonidos que se imponen, que son capaces de saturarlo todo y de destruir todo acto posible de escucha. El sonido cuya medida vemos en la pantalla y que traspasa la línea roja es la voz de Adolf Hitler durante sus mítines políticos o durante sus discursos radiofónicos. Escuchamos la voz en off del propio Godard que afirma que siempre ha habido un momento en el tiempo en que un sonido toma el poder de los demás. Existe un punto en el tiempo en el que un sonido busca de forma desesperada la posibilidad de conservar dicho poder. ¿Cómo fue posible que este sonido tomara el poder? El sonido tomó el poder porque, en un momento determinado, se hizo representar por una imagen. A partir de aquí, Godard empieza a establecer un collage entre la imagen del presidente de los Estados Unidos, Richard Nixon, y la imagen del político y militar israelita Moshe Dayan. 
Godard piensa que el sonido ayuda a representar la imagen que permite tomar el poder como icono de la sociedad de su época.

La idea de utilizar el sonido como metáfora política vuelve a estar presente, con la misma voluntad polémica en un momento de JLG par JLG (1995), un interesante trabajo autobiográfico planteado como un ensayo de reflexión íntima llevado a cabo por el propio Godard. En un momento de su ensayo fílmico, vemos al cineasta frente a una hoja de papel en blanco, en la que desea llevar a cabo una demostración dibujada sobre el proceso de creación de la estereofonía sonora. Godard empieza afirmando que el estéreo fue creado por los perros y los ciegos. Frente a la hoja en blanco, dibuja un triangulo, mientras indica que el sonido estéreo se desplaza desde un punto concreto hacia dos altavoces que difunden el sonido. La figura que crea este desplazamiento es triangular. En otro punto, muestra al espectador que escucha y mira. Desde un punto concreto, el espectador necesita capturar el sonido de los dos puntos sonoros de la estereofonía. Esto provoca la creación de un triangulo invertido. El resultado final, a partir de la combinación de los dos triángulos, no es otro que la estrella de David, símbolo del judaísmo.

Además de estos ejemplos tan clarividentes, vemos cómo la metáfora sonora es utilizada otras veces por Godard para llevarnos hacia la historia y la política, poniendo en evidencia el sentido crítico que el cineasta siempre ha mostrado ante las políticas del Estado de Israel. Este factor no ha estado ausente de cierta controversia que ha servido para que algunos sectores lo acusaran de cineasta antisemita (Darmon, 2011: 14). Dejando de lado las polémicas, resulta curioso observar cómo, en numerosos ensayos suyos como Scénario du film Passion (1982) o JLG par JLG (1995), Godard aparece dentro de su estudio rodeado de numerosos monitores de video y diferentes aparatos de amplificación. Otras veces, como en King Lear (1987), aparece con la cabeza cubierta por diversos cables de sonido y de video. El cineasta quiere focalizar su mirada hacia su espacio de creación, de modo parecido a como en otras ocasiones se ha propuesto filmar los músicos, y pensar de qué modo el sonido no es más que el elemento fundamental para entender una dialéctica creativa basada en repensar cual es el espacio de pensamiento generado después de escuchar un sonido y de ver una imagen.

\section{Referencias}

\section{Bibliografía}

Bergala, Alain, ed. (1985). Jean Luc Godard par Jean Luc Godard, 1. París: Cahiers du cinéma.

néma.

(1998). Jean-Luc Godard par Jean-Luc Godard, 2. París: Cahiers du ci- 
Ángel Quintana. Algunos apuntes sobre el uso del sonido en el cine de Jean-Luc Godard.

Bergala, Alain (2006). Godard au travail. París: Cahiers du cinéma.

Darmon, Maurice (2011). La question juive de Jean Luc Godard. París: Le temps qu'il fait.

De Baecque, Antoine (2010). Godard. Biographie. París: Grasset.

Eisenstein, Sergei. (2001). Hacia una teoría del montaje, Vol. 2. Barcelona: Paidós.

Gubern, Román (1969). Godard Polémico. Barcelona: Tusquets.

Jullier, Laurent (2004). JLG / ECM. En Michael Temple, James Williams y Michael Witt. For Ever Godard. London: Black Dog Publishing. 272-287.

Liandrat-Guigues, Suzanne; Leutrat, Jean-Louis (1994). Jean Luc Godard. Madrid: Cátedra.

MacCabe, Colin (1980). Godard, images, sounds, politics. Londres: British Film Institute.

(2005). Godard: A Portrait of the Artist at Seventy. Nueva York: Farrar, Straus and Giroux.

Sánchez-Biosca, Vicente (1996). El montaje cinematográfico. Barcelona: Paidós.

\section{Filmografía}

Godard, Jean-Luc (director) (1960). À bout de souffle. 90 min. Francia: Beauregard / SNC / Impéria.

(1961). Une femme est une femme. Francia / Italia: Rome-Paris Films / EIA - Euro International Film.

(1962). Vivre sa vie. 80 min. Francia: Les Films de la Pléiade, Pathé Consortium Cinéma.

(1963). Le Mépris. 110 min. Francia / Italia: Rome-Paris Films,

Les Films Concordia.

(1964). Bande à part. 95 min. Francia: Anoucka Films, Orsay

Films.

(1964). Une femme mariée. 98 min. Francia: Anouchka Films,

Orsay Films.

(1965). Alphaville. 98 min. Francia / Italia: Chaumiane Productions /

Filmstudio.

(1966). Made in USA. 52 min Francia: CinéCinéma.

(1968). Sympathy for the Devil. 100 min. Gran Bretaña: Cupid

Productions.

(1970). British Sounds. 52 min. Gran Bretaña: Kestrel Produc-

tions, LWT - London Weekend Television.

(1982). Lettre à Freddy Buache. 11 min. France. 
(1982). Passion. 87 min. Francia / Suiza: Les Films A2, Sara Films, Sonimage / Film et Video Productions, RTS - Radio Télévision Suisse.

(1983). Prénom Carmen. 85 min. Francia: Sara Films, JLG Films, Films A2.

(1987). Soigne ta droite. 82 min. Francia / Suiza: Gaumont, JLG Films, Xanadu Films / Radio Télévision Suisse Romande.

Globus Productions.

(1987). King Lear. 90 min. EEUU: The Cannon Group, Golan

(1988-1998). Histoire(s) du cinéma. 8 capítulos. Francia: Ca-

nal+.

(1982). Scénario du film Passion. Francia / Suiza: JLG Films / Radio Télévision Suisse Romande.

(1995). JLG par JLG. 62 min. Francia: Gaumont.

(2010). Film socialisme. 102 min. Francia / Suiza: Wild Bunch, Canal+ / Vega Film AG, Radio Télévision Suisse Romande, Suissimage.

(2014). Adieu au langage. 70 min. Francia: Wild Bunch.

Godard, Jean Luc; Miéville, Anne-Marie (directores). (1970). Ici et ailleurs. 60 min. Francia: Sonimage, INA - Institut National de l'Audiovisuel.

Renoir, Jean (director) (1932). La nuit du carrefour. 75 min. Francia: Europa Films.

Resnais, Alain (director) (1959). Hiroshima mon amour. 91 min. Francia / Japón: Argos Films, Como-Films, Pathé Overseas / Daiei Motion Picture Company.

(1961). L'année dernière à Marienbad. 93 min. Francia / Italia: Terra Film, Société Nouvelle des Films Cormoran, Précitel, Como-Films, Argos Films, Les Films Tamara, Cinétel, Silver Films / Cineriz. 